This item was submitted to Loughborough's Research Repository by the author.

Items in Figshare are protected by copyright, with all rights reserved, unless otherwise indicated.

\title{
What is the relationship between human factors \& ergonomics and quality improvement in healthcare?
}

PLEASE CITE THE PUBLISHED VERSION

http://www.routledge.com/9781138028036

\section{PUBLISHER}

(C) Taylor \& Francis

\section{VERSION}

AM (Accepted Manuscript)

\section{PUBLISHER STATEMENT}

This work is made available according to the conditions of the Creative Commons Attribution-NonCommercialNoDerivatives 4.0 International (CC BY-NC-ND 4.0) licence. Full details of this licence are available at: https://creativecommons.org/licenses/by-nc-nd/4.0/

\section{LICENCE}

CC BY-NC-ND 4.0

\section{REPOSITORY RECORD}

Hignett, Sue, Duncan Miller, Laurie Wolf, Emma L. Jones, Peter Buckle, and Ken Catchpole. 2019. "What Is the Relationship Between Human Factors \& Ergonomics and Quality Improvement in Healthcare?". figshare. https://hdl.handle.net/2134/23496. 


\title{
WHAT IS THE RELATIONSHIP BETWEEN HUMAN FACTORS \& ERGONOMICS AND QUALITY IMPROVEMENT IN HEALTHCARE?
}

\author{
Sue Hignett ${ }^{1}$, Duncan Miller ${ }^{2}$, Laurie Wolf ${ }^{3}$, \\ Emma Jones $^{4}$, Peter Buckle ${ }^{5}$, Ken Catchpole ${ }^{6}$ \\ ${ }^{1}$ Loughborough University, UK \\ ${ }^{2}$ Sheffield Teaching Hospitals NHS Foundation Trust, UK \\ ${ }^{3}$ Barnes Jewish Hospital, St Louis, Missouri, USA \\ ${ }^{4}$ Department of Health Sciences. University of Leicester, UK \\ ${ }^{5}$ Royal College of Art, London, UK \\ ${ }^{6}$ Cedars Sinai Medical Centre, Los Angeles, USA
}

\begin{abstract}
A recent initiative in the National Health Service (NHS, UK) has led to an increased interest in Human Factors \& Ergonomics (HFE). As part of initial discussions there have been questions about the similarities and differences between HFE and Quality Improvement (QI). We believe that there are considerable advantages from a more structured relationship between HFE and QI in healthcare and have comparatively mapped a range of dimensions (origins, drivers, philosophy, focus, role and methods). Our conclusion is that HFE in healthcare should use four criteria to maximise the benefits from this opportunity, including the use of HFE methods to design systems, environments, products etc. and the direct involvement of qualified (chartered) HFE professionals.
\end{abstract}

\section{Introduction}

There is a renewed interest in applying an HFE approach for patient safety issues in the UK (National Quality Board, 2013). Sixteen healthcare agencies have signed a statement 'that a wider understanding of Human Factors principles and practices will contribute significantly to improving the quality (effectiveness, experience and safety) of care for patients'

At two initial meetings it became apparent that there was considerable confusion about whether HFE was a new initiative or was already being achieved through QI projects. This paper explores and maps the relationship between HFE and QI in healthcare. 


\section{HFE and QI in healthcare}

\section{Human Factors \& Ergonomics}

The need for HFE in healthcare has been recognised since the inception of the profession and discipline but development and growth have been slow (Carayon, 2010) with a dysfunctional separation of the human elements in healthcare systems into occupational health (and operational excellence) for staff, and patient safety (Hignett et al, 2013). This misconception and limited application of HFE is apparent within training programmes for non-technical skills for surgeons (NOTSS; Yule et al, 2008). This has, in our opinion, contributed to the tendency to blame 'the failures of people as the underlying cause of adverse events or broken healthcare delivery processes, a stance that is contrary to human factors science and counterproductive for advancing patient safety' (Russ et al, 2013a) as 'little attempt is made to explore and address the underlying systemic causes that lead to errors' (Russ et al, 2013b). Catchpole (2013) has commented that 'this behavioural safety approach, while entirely legitimate and increasingly well evidenced, is limited. Yet, it has dominated perceptions of what constitutes HF and shaped the application of HF principles in healthcare. Frequently espoused by well-meaning clinicians and aviators, rather than academically qualified HF professionals, it has led to misunderstandings about the range of approaches, knowledge, science and techniques that can be applied from the field of HF to address patient safety and quality of care problems.'

\section{Quality Improvement}

Quality initiatives have been used in the UK healthcare system for over 30 years, with as 'sporadic efforts to implement quality circles and TQM [Total Quality Management]... in the 1980s and early 1990s'(Ferlie and Shortell, 2001). These early initiatives focused more on organisational performance and efficiency than safety. Quality and safety were not explicitly linked in healthcare until the late 1990 s as 'the language of error and harm had not entered healthcare discourse' (Vincent, 2010). Initiatives to link quality and safety in the NHS derived from clinical governance (mid 1990s; Scally \& Donaldson, 1998) which gained prominence following the Bristol heart scandal (1984-1995; DH, 2002) and included clinical audit, clinical effectiveness, education and training, research and development, openness, risk management, and information management. The Commission for Health Improvement (CHI, 1999-2004; Day and Klein, 2004) redefined clinical governance as 7 pillars; patient involvement, clinical audit, risk management, staffing and management, education and training, clinical effectiveness, and use of information. This was followed firstly by the Commission for Health Audit and Inspection (CHAI, 2004-2009) also known as the Healthcare Commission (Haslam, 2007), with a slightly different remit, philosophy and expanded role; and then, secondly by the Care Quality Commission (2009-). There have also been advisory and arms-length bodies with a role in the quality agenda including National Quality Board (2009-), the National Patient Safety Agency (2001-2012), NHS Institute for Innovation and Improvement (2005-2013; including the Productive series and Quality, 
Innovation, Productivity \& Prevention (QIPP) work streams), and more recently NHS Improving Quality (2013-).

\section{Comparing HFE and QI}

A very simple comparison suggested by the authors is that:

- HFE projects look at the humans and the system, and then re-design the tasks, interfaces and the system (Fig. 1), whereas

- QI projects look at the system and then change the humans with the focus on meeting the needs of the customer demand and not necessarily considering the individual worker or optimal efficiency.

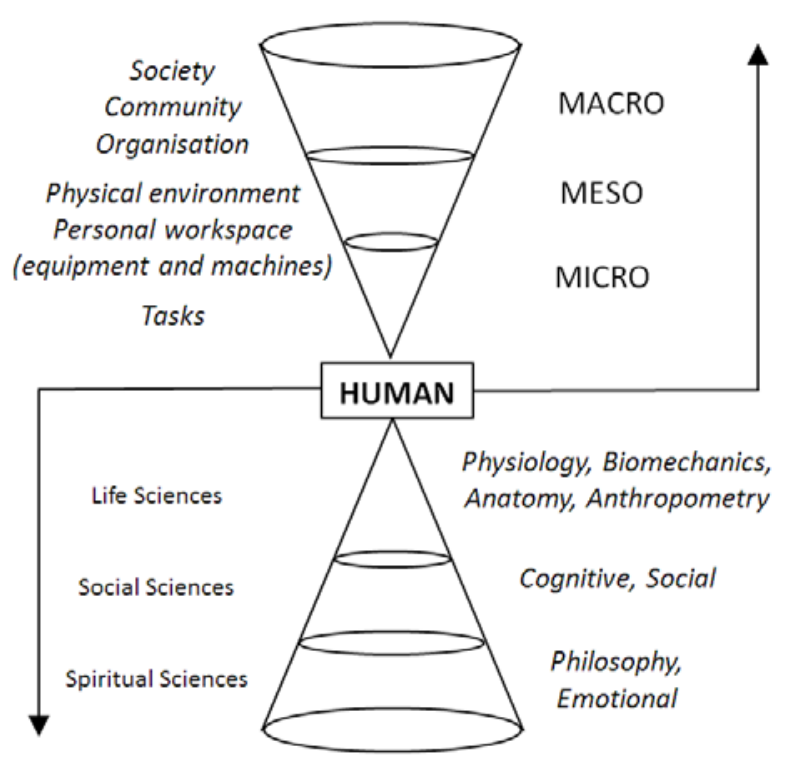

Figure 1. Human Interactions model (Hignett, 2001)

This evolution of QI in healthcare has resulted in a range of definitions for QI in healthcare including any change which improves quality (patient experience and/or clinical outcome); a change that uses a generic (e.g. training, setting standards) or specific method for a quality improvement change (e.g. Plan-DoStudy-Act); or a QI approach e.g. re-engineering, Six Sigma, Lean (Øvretveit, 2009).

The term 'Ergonomics' has been used for professional practice in the UK from 1950 (and internationally from 1961) whereas the term 'Human Factors' was 
used in the USA from 1957. These terms have been harmonised in US, UK, Australia and New Zealand by the inclusion of both Ergonomics and Human Factors in Society, Institute and Association names. Most non-English speaking countries continue to use the term Ergonomics. In 2000 an international definition was agreed: 'Ergonomics (or Human Factors) is the scientific discipline concerned with the understanding of interactions among humans and other elements of a system, and the profession that applies theory, principles, data and methods to design in order to optimise human well-being and overall system performance' (IEA, 2000).

The philosophy of the disciplines have diverged from a similar origin of engaging workers in the identification of problems and development of solutions. Both developed in the $20^{\text {th }}$ century; QI in response to production quality control (reduction in errors and cost) and HFE to improve worker safety and performance as an integration of occupational health, engineering design, physical/cognitive behaviours (human and health sciences) and socio-technical systems. QI initiatives often seek to eliminate waste (Lean) and decrease variation (Six Sigma) using systematic data-driven continuous improvements and process redesign. The drivers for QI are mostly linked to performance (commissioning or reimbursement), for example through the Commissioning for Quality and Innovation (CQUIN) framework (UK) which aims to 'support improvements in the quality of services and the creation of new, improved patterns of care. It is intended to complement our approach to the payment system, providing a coherent set of national rules' (NHS Commissioning Board, 2014). Drivers for HFE are to improve both productivity and human wellbeing (including safety). HFE uses task and systems analyses to understand and map human variance and re-design the interfaces, environments and systems based on principles of individual participation and inclusion.

Eklund (1997) suggested that 'several aspects of TQM ... have potential to violate ergonomics [HFE] principles', for example 'standardisation, ... reduction of variability, copying of best practice, reward systems and heavy demands on cost reduction for customer benefit.' The role of QI and HFE professionals may be similar for the facilitation of change but differ with respect to focus (despite both using the same terminology; micro-meso-macro). In HFE, 'micro' refers to individual, human abilities and limitations, whereas in QI 'micro' refers to a team level (staff - patient). There are some overlaps in the methods used (for example systems analysis with Failure Modes Effect Analysis, FMEA) but the two professions mostly use different methods (Table 1). 
Table 1. Comparison of some of the methods used in HFE and QI

\begin{tabular}{|c|c|}
\hline HFE & QI \\
\hline $\begin{array}{l}\text { Systems Concepts } \\
\text { Structure and dynamics of systems; } \\
\text { sociotechnical systems theory, } \\
\text { human-automation interaction } \\
\text { (machine/computer), systems } \\
\text { analysis and design. } \\
\text { Integrated view of human } \\
\text { characteristics (physical, } \\
\text { psychological, social); } \\
\text { Participatory ergonomics. } \\
\text { Design Concepts } \\
\text { Task analysis to understand and map } \\
\text { human variance (Hierarchical Task } \\
\text { Analysis, Link Analysis, Verbal } \\
\text { Protocol Analysis, Postural } \\
\text { Analysis); Anthropometry; } \\
\text { Translation of general design } \\
\text { principles, standards, guidelines and } \\
\text { regulations into project specific } \\
\text { requirements; User-centred design, } \\
\text { HFE impact on product design cycle, } \\
\text { inclusive (universal) design. } \\
\text { Limitations of technology (promises, } \\
\text { pitfalls and realities). }\end{array}$ & $\begin{array}{l}\text { Understand the process using data and } \\
\text { patient experience; understand demand, } \\
\text { capacity and flow. } \\
\text { Business process re-engineering; Plan, } \\
\text { Do, Study Act (PDSA); Statistical } \\
\text { Process Control. } \\
\text { Lean: Continuous improvement based } \\
\text { on short term snapshots. Eliminate } \\
\text { waste by continuously striving for } \\
\text { value added to the customer; Observe } \\
\text { workplace; Value stream mapping; } \\
\text { Rapid improvement event; 5S (sort, } \\
\text { straighten, shine, standardize, sustain). } \\
\text { Six Sigma: Decrease variation, by a } \\
\text { systematic data driven process - } \\
\text { Define-Measure-Analyse-Improve- } \\
\text { Control (DMAIC). Gauge } \\
\text { Repeatability \& Reproducibility } \\
\text { SIPOC (Supplier, Input, Process, } \\
\text { Output, Customer); Process mapping; } \\
\text { Design of Experiment; Voice of } \\
\text { Customer; Culture change methods; } \\
\text { Stakeholder assessment; Statistics \& } \\
\text { control limits. }\end{array}$ \\
\hline
\end{tabular}

\section{Discussion and Conclusion}

The first challenge in implementing the National Quality Board Concordat (2013) is to spread and embed an understanding of HFE and how it differs from QI across the 16 signatory organisations: Care Quality Commission, Department of Health, Health Education England, NHS Employers, NHS England, NHS Trust Development Authority, Monitor, The Parliamentary \& Health Service Ombudsman for England, National Institute for Health and Care Excellence, Public Health England, General Medical Council, HealthWatch England, NHS Litigation Authority, Nursing and Midwifery Council, Social Care Institute for Excellence, NHS Leadership Academy.

There has been a gradual increase in the application of HFE in healthcare (Hignett et al, 2013). As the importance and relevance of HFE in healthcare has grown there are examples of bright and action-oriented healthcare professionals interested in safety and quality rushing off to 'do human factors' with only a 
superficial understanding of the fundamental concepts, resulting in ' $d o$ it yourself' HFE (Saleem et al, 2011). This should be of concern to the HFE professional community as 'medical [clinical] education does not necessarily provide a good preparation to understand the ideas and literature of other fields' (Kneebone, 2002), for example engineering, psychology and design.

We suggest the relationship between HFE and QI could be described as similar to that between the disciplines and professions of Medicine and Dentistry; similar origins and drivers but differences in focus and methods. There are considerable advantages from a more structured relationship between HFE and QI. For example QI practitioners often identify problems and bring expertise in training and facilitating change but may lack an understanding of individual human behaviours (physical and cognitive interactions and capabilities) that are needed to develop solutions and interventions. In contrast HFE practitioners may have less expertise in process redesign, measuring variance and implementing recommendations.

To increase the use of HFE in healthcare we recommend that the following four criteria should be used to benchmark the quality of all HFE training and professional input (derived from Carayon et al, 2014):

1. Use of HFE tools

2. Use of HFE knowledge

3. Application of HFE to the design of equipment, medical devices, products, buildings, vehicles and systems

4. Direct involvement of qualified HFE professionals (registered/chartered member of a federated society of the International Ergonomics Association (http://www.iea.cc/about/council.html)

\section{References}

Carayon, P. 2010, "Human factors in patient safety as an innovation". Applied Ergonomics 41(5): 657-665.

Carayon, P., Xie, A. and Kianfar, S. 2014. "Human factors and Ergonomics as a patient safety practice”. BMJ Quality \& Safety 23:196-205.

Catchpole, K. 2013. "Spreading Human Factors expertise in Healthcare: Untangling the knots in People and Systems”. BMJ Quality \& Safety 22:793-797.

Day, P. and Klein, R. 2004. The NHS Improvers. A study of the Commission for Health Improvement. London: The Kings Fund.

DH 2002. Learning from Bristol. The Department of Health's response to the report of the Public Inquiry into children's heart surgery at the Bristol Royal Infirmary 1984-1995. London: TSO. 
Eklund, J. 1997. "Ergonomics, quality and continuous improvement: conceptual and empirical relationships in an industrial context.” Ergonomics 40:981001.

Ferlie, E.B. and Shortell, S.M. 2001. Improving the quality of healthcare in the United Kingdom and the United States: A framework for change. The Milbank Quarterly 79:281-315.

Haslam, D. 2007. What is the Healthcare Commission trying to achieve? Journal of the Royal Society of Medicine, 100:15-18.

Hignett, S., Carayon, P., Buckle, P. and Catchpole, K. 2013. "State of science: human factors and ergonomics in healthcare.” Ergonomics 56:1491-1503.

Hignett, S. 2001. "Using Qualitative Methodology in Ergonomics: Theoretical Background and Practical Examples”. Ph.D. Thesis. University of Nottingham.

IEA. 2000. International Ergonomics Association, Triennial Report. Santa Monica, CA: IEA Press. 5.

Kneebone, R. 2002. “Total internal reflection: an essay on paradigms”. Medical Education, 36(6):514-518.

National Quality Board. 2013. Human Factors in Healthcare. A Concordat http://www.england.nhs.uk/wp-content/uploads/2013/11/nqb-hum-factconcord.pdf (Accessed 25th August 2014)

NHS Commissioning Board. 2014 Commissioning for quality and innovation (CQUIN): $\quad$ guidance http://www.england.nhs.uk/wpcontent/uploads/2014/02/sc-cquin-guid.pdf (Accessed 10 Oct 2014)

Øvretveit, J. 2009. "Does improving quality save money? A review of evidence of which improvements to quality reduce costs to health service providers". The Health Foundation. http://www.health.org.uk/publications/doesimproving-quality-save-money/ (Accessed 6 Dec 2014)

Russ, A.L., Fairbanks, R.J., Karsh, B-T., Militello, L.G., Saleem, J.J. and Wears, R.L. 2013a. "The Science of Human Factors: separating Fact from Fiction." BMJ Quality \& Safety. 22:802-808.

Russ, A.L., L.G.Militello, J.J. Saleem, et al. 2013b. "Response to separating Fact from Opinion: a Response to 'the science of Human Factors: separating Fact from Fiction”. BMJ Quality \& Safety 22:964-966.

Saleem, J.J., E.S Patterson, A.L. Russ, and R.L. Wears. 2011. "The need for a broader view of human factors in the surgical domain”. Arch Surg 146(5):631-632.

Scally, G. and Donaldson, L. 1998. "Clinical governance and the drive for quality improvement in the new NHS in England”. BMJ 317:61

Vincent, C. 2010. Patient Safety. $2^{\text {nd }}$ Ed. Chichester, West Sussex: John Wiley \& Sons Ltd 35.

Yule, S., Flin, R., Maran, N., Rowley, D., Youngson, G. and Paterson-Brown, S. 2008. "Surgeons' Non-technical Skills in the Operational Room: Reliability Testing of the NOTSS Behaviour Rating System”. World J Surg 32:548556. 